\title{
FROM ROBO-SAPIENS TO ROBO-LUDENS: RE-THINKING FUTURE LEARNING WITH SMART PERSONAL DIGITAL PLAYMATES
}

\author{
Dr. Sezan SEZGIN \\ ORCID: 0000-0002-0878-591X \\ Faculty of Education \\ Burdur Mehmet Akif Ersoy University \\ Burdur, TURKEY
}

Received: 19/05/2019 Accepted: 10/09/2019

\begin{abstract}
This systematic review investigates two foci: identifying the ongoing status of smart personal digital assistants in educational contexts and the possible relationship between smart personal digital assistants and gamification elements. This relationship is expressed in almost two new figurative terms, namely, robosapiens and robo-ludens and the present study lays on the foundations of these terms. Therefore, this paper presents a holistic approach for the review and synthesis of the previous literature. The data of the study were gathered based on the findings reported in the related research articles, conference papers, dissertations, book chapters and project reports by focusing on 9 sets of generic keywords. As a part of this study, smart personal digital assistants in learning processes were scanned purposively in the lens of gamification. To this end, a two step inclusion criteria was implemented to review the studies of the research scope. Content analysis was the main method used for data analysis. The research findings revealed the most significant fields for the use of smart personal digital assistants are dominantly e-learning and special education. The research also discusses game-related components in smart personal digital assistant use in edu-centric purposes.
\end{abstract}

Keywords: Smart personal digital assistants, robo sapiens, robo ludens, play behaviour, digital playmates

\section{INTRODUCTION}

Technology is a transformative power and shapes human life at a faster pace than ever before (TiroshSamuelson \& Mossman, 2011). In the current Internet of things (IoT) era in which most of the devices are connected with other devices by broad wireless network technologies and sensors (Gomez, Chessa, Fleury, Roussos, \& Preuveneers, 2019), it is a general acceptance that the learning ways of individuals are changing. Therefore, individual differences are at the core point of learning processes in todays data-oriented world and it is crucial for researchers and educators to take into consideration these changes to provide rich educational experiences. This paper fundamentally seeks to emphasise on learning analytics and methods of data gathering from individuals via smart personal digital assistants (SPDAs). The starting point of this emphasis arises from the difficulty of gathering the required datas of individuals in learning contexts. This study was conducted in direct response to this difficulty and aims to spot possible abilities and roles of SPDAs in educational settings. Another topic that is addressed in this study is the game related patterns in SPDA use. Game related contexts and applications are considered to be important agents in the data chaotic world of knowledge due to their attention-grabbing nature. Gamified content/applications will very likely to be a solution and a helper to gather learning analytics.

The paper is organized as follows; a bacground of concepts and figurative terms used to describe the general structure about the SPDAs and gamified assistants is given in the first section starting with background of the study. Section 2 describes the methodological approach and details of inclusion and exclusion criterias as well as limitations of the study. In section 3, findings are given in a coherent manner. Finally, conclusions and future implications are given in section 4 . 


\section{BACKGROUND}

Robo-Sapiens is a term that describes human-like intelligence for intelligent embodied systems, and it is a clear reference to the term Homo Sapiens (Back, Zant \& Zwanepol Klinkmeijer, 2001). Another figurative term, namely robo-ludens is originated from the influential book of Huizinga (1955), Homo Ludens. This term was used in the PhD dissertation written by Iantorno (2015) and a conference abstract by Soma (2018). Robo ludens describes human-like intelligence that plays a role as the playmates of humans. These terms have been used in different studies, although they are considerably new terms. Studies that includes the terms robo-sapiens and robo-ludens are shown in Table 1. This table actually shows the trend of ongoing transformation in technology inovations between artificial intelligence and human daily life.

Table 1. Studies that includes the terms robo-sapiens and robo-ludens

\begin{tabular}{|c|c|c|c|}
\hline Author & Year & Name of the paper & \\
\hline Menzel, P., \& d'Aluisio, F. & 2001 & Robo sapiens: Evolution of a new species & Robo-sapiens \\
\hline $\begin{array}{l}\text { Back, W. D., Zant, T., \& Zwanepol } \\
\text { Klinkmeijer, L. }\end{array}$ & 2001 & $\begin{array}{l}\text { Robo Sapiens. Proceedings of the First Dutch Symposium } \\
\text { on Embodied Intelligence. }\end{array}$ & Robo-sapiens \\
\hline Negrete-Martinez, J. & 2005 & Three Steps to Robo Sapiens & Robo-sapiens \\
\hline Robertson, J. & 2007 & $\begin{array}{l}\text { Robo sapiens japanicus: Humanoid robots and the } \\
\text { posthuman family }\end{array}$ & Robo-sapiens \\
\hline Hayles, N. K. & 2010 & $\begin{array}{l}\text { My mother was a computer: Digital subjects and literary } \\
\text { texts }\end{array}$ & Robo-sapiens \\
\hline $\begin{array}{l}\text { Tirosh-Samuelson, H., \& } \\
\text { Mossman, K. L. }\end{array}$ & 2012 & $\begin{array}{l}\text { New perspectives on transhumanism. Building better } \\
\text { humans }\end{array}$ & Robo-sapiens \\
\hline Watkins, S. & 2012 & $\begin{array}{l}\text { Future Shock: Rewriting the Apocalypse in Contemporary } \\
\text { Women's Fiction }\end{array}$ & Robo-sapiens \\
\hline $\begin{array}{l}\text { Guadagno, R. E., Okdie, B. M., \& } \\
\text { Muscanell, N. L. }\end{array}$ & 2013 & $\begin{array}{l}\text { Have we all Just Become "Robo-Sapiens"? Reflections on } \\
\text { social influence processes in the Internet age }\end{array}$ & Robo-sapiens \\
\hline Kim, M. S., \& Kim, E. J. & 2013 & $\begin{array}{l}\text { Humanoid robots as "The Cultural Other": are we able to } \\
\text { love our creations? }\end{array}$ & Robo-sapiens \\
\hline Gutierrez-Jones, C. & 2014 & Stealing Kinship: Neuromancer and Artificial Intelligence & Robo-sapiens \\
\hline $\begin{array}{l}\text { van de Gevel, A. J., \& Noussair, } \\
\text { C. N. }\end{array}$ & 2015 & $\begin{array}{l}\text { Artificial Intelligence and Economics: from Homo Sapiens } \\
\text { to Robo Sapiens. }\end{array}$ & Robo-sapiens \\
\hline McCulloch, F. & 2016 & $\begin{array}{l}\text { "No Longer Just Human": The Posthuman Child in Beth } \\
\text { Revis's Across the Universe Trilogy }\end{array}$ & Robo-sapiens \\
\hline lantorno, M. & 2015 & Conceptualizing Robots As Playmates and Playthings & Robo-ludens \\
\hline Soma, N. & 2018 & $\begin{array}{l}\text { Utopia of } 81 \text { Squares: Harmony between homo/robo } \\
\text { ludens in Shogi and Chess. }\end{array}$ & Robo-ludens \\
\hline
\end{tabular}

\section{Two New Species: Transhumans and Robo-Sapiens}

The starting point of this review is the parabolic advancement in SPDA technologies. As a "futuristic vision", SPDAs are supposed to be the major actors as data gathering tools and act as digital playmates of individuals. The significancy this current research lays on the technological transformation progress, is explained briefly in this part of the study according to reach a comprehensive understanding.

Most researchers trace the earliest use of the term "transhumanism" to Julian Huxley's 1957 essay of the same name (Mercer \& Trothen, 2014, p. 64). But this term likely appears even earlier in 1927 . Huxley described transhumanism as "self-evoluation of humanism" as well as a period when humanism is transcending himself. Huxley seems to be right in this description of the term. Technological kinesis, including super-computers, sensors, wireless connectivity, artificial intelligence, robotics, neural networks, advancements in nature and human modelling, etc., brings new horizons and possibilities for homo-sapiens to eliminate or at least reduce biological barriers (Postman, 1993) and to transform the limits of self (Klinger \& Coffman, 2019).

Human-integrated or environmental sensors gather our data, making it possible for us and others to have much more information about our lives (Rushe, 2010). These data are used to improve individuals' health, education, social relations and life skills. Potential improvements can be realized very fast, faster 
than the overall human capacity. So, "assisting humans' capacity with technology" is the main subject of transhumanism. It is possible to give an example about a smart optical contact lens: This lens can focus on and zoom in distant objects optically by eye movements of individuals. Normally a homo-sapien can not see the details of small objects using his unaided eye if the object is too distant. By the assistance of smart lens, the natural capacity of vision can be improved substantially. Therefore, assisting technology add-ins created a new era that may possibly transform humans into transhumans. Transhumanist age is a period of change that technology may help homo-sapiens to evolve into a new species (Coursen, 2011) called transhuman or "transitional human" (Tirosh-Samuelson \& Mossman, 2011), which is much more developed and technologically aided human (Grant, 2019).

Moravec's (1999) hypothesis claims that in the medium run (around 2050, transhumanistic period), smart machines will be capable of performing policy-making, public relations, law or some professions like engineering. Transhumans and artificial intelligence agents will be the major actors together (Hayles, 1999; p.2) of this period. Some futurists argue that transhumanistic period will bring another new species, namely posthumans: "persons of unprecedented physical, intellectual and psychological capacity, self-programming, potentially immortal, unlimited individuals" (More, 2004). Moravec (1999) also states that this will be "an inevitable process" in which robots will replace individuals in many fields.

Although technological improvements develop a similar view, it is not necessary to be so pessimistic. The transhumanist philosophy claims that there is a third alternative. Coursen (2011) specifically argues that this alternative is based on self-reflective capacity of humans stating that "a capacity that seemingly separates it from other biological species". Therefore, humans may design and create a posthuman species that can behave and act as themselves with self-oriented perfectionism but also obedient. The possible new species, namely robo-sapiens, is very likely to appear in the future stage of history. The term robo-sapiens, which is a thinking and conscious robot is a clear reference to the term homo sapiens. In this paper, the term robosapiens is used as a representative of human-like intelligence for intelligent embodied systems like todays' smart personal assistants.

\section{Gathering Daily Life Analytics from Learners via Games: Robo-sapiens turns into Robo-Ludens}

Play is a very common and one of the basic instinctual actions of humans. Humans begin to learn and to observe the world through the lens of games. Therefore, playing games is one of the most natural ways of learning for homo-sapiens. In this sense, the educational power of games and playing action is an open field for researchers and educators (Sezgin \& Yuzer, 2017). Gamification and game based learning are the two approaches that integrate the educational potential of games into learning process (Sezgin, Bozkurt, Yilmaz, $\&$ van der Linden, 2018). On the other hand, using game-centered processes is one of the effective ways to interact with people.

In order to establish the effectiveness of teaching and learning processes, those who design such processes must take individual differences into consideration. In regard to the specialised teaching practices, getting and evaluating a number of individual data, learning analytics, is a vital concern for educators. The analyzable and essential educational data (Baker \& Inventado, 2014) can be gathered and made available for the analysis by the help of sensors and digital devices. The collection of the data on a sample of learners is generally a difficult process. However, here the real challenge is to gather the data required in situation-based knowledge contexts. In order to avoid this challenge, artificial intelligence agents which uses gaming components and interacts with the learner are one of the common ways of gathering the analytics needed.

One of today's cutting edge technological innovation of ongoing transhumanist age is smart personal digital assistants (SPDAs). The advancement of mobile technologies has made the artificial intelligence very close to daily life (Maedche, Legner, Benlian, Berger, Gimpel, Hess, ... \& Sollner, 2019). Smart phones and other mobile devices use SPDAs to help people in organizing their daily routines, managing their time effectively and also having basic decision support. In other words, the SPDAs are used by individuals as "an interactive peer on a daily basis" (Kanda et al. 2004). SPDAs are also representations of human to robot interaction across communication contexts in everyday life (Kim et al. 2011). It is possible to state that playing robo-sapiens which may be called as robo-ludens, are the future game-changer assistants of educators in the near future. 
There are several distinct SPDAs used today. Apple's Siri, Google Assistant, Microsoft's Cortana, Bixby, Amazon Alexa, Google's Now, Samsung Viv, Nuance’s Nina, True Knowledge Evi, LG Voice Mate, Microsoft's Braina are the most known SPDAs. The usage of SPDAs are generally based on forecasting, navigation, tutoring, translation, infotainment, health care, tutoring and gamifiying.

There are not so many studies that reviews the existing literature about the SPDAs. In Bozkurt and Goksel's (2018) comprehensive review, the intelligent personal assistants (IPAs) were reviewed, and some of the key concepts about IPAs were identified by examining 34 years of IPA research. The study also emphasized the educational use of the IPAs. It was concluded that artificial intelligence is a core concept in the IPA research and that the IPAs emerge as a promising research area for educational settings by increasing the degree of perceived social presence (Bozkurt \& Goksel, 2018).

This study deals with the smart personal digital assistants in relation to gamification and their potential roles for educational contexts. In this regard, the study intended to shed light on the following research questions:

1. What are the the most significant fields of application / subject areas for the use of smart personal digital assistants in educational contexts?

2. What are the game-related components and fields of applications in smart personal digital assistant publications in edu-centric purposes?

\section{METHODOLOGY}

This study uses a concept-centric holistic approach to systematically review and synthesize the related literature about SPDAs. This type of studies are helpful to form a holistic view about the related research domains and to identify general tendency of knowledge development (Petticrew \& Roberts, 2005; Webster \& Watson, 2002). The inital aim of a systematic literature review is to provide a comprehensive review and synthesis of the studies available in a particular research area. In line with this, the systematic review of the former studies and meta-synthesis are the two interwoven approaches used in this study to reach a conceptcentric holistic view.

This study is also a comprehensive meta-synthesis that seeks to understand the possible roles of the SPDAs in the educational/learning processes and gamification. The meta-synthesis is a research approach that brings together the results of different studies which deal with a similar subject (Walsh \& Downe, 2005). Accordingly, peer reviewed research articles, conference papers, book chapters, project reports and dissertations were all used as the main sources for the data collection process. In addition, the educational online artefacts were also used to construct a general overview and to see the different dimensions to get a complete understanding about the research topic. As part of this study, the studies concerning the SPDAs were also reviewed with the lens of gamification in learning contexts.

\section{Inclusion and Exclusion Criteria}

In order to find the related studies, the following key terms were used: "smart assistant", "intelligent assistant", "artificial assistant", "interactive assistant", "virtual assistant" and "personal digital assistant", "personal assistant \& learning", "personal assistant \& teaching", "personal assistant \& education". In order to construct a sample of the related studies the snowball sample technique was employed which enabled the authors to reach more related studies. The studies reviewed in this study were found and listed via Google Scholar, Scopus, Web of Science and Proquest indexes. Also project reports listed in Google Scholar and CORDIS (which is the primary source of results from EU-funded projects since 1990) were used to reach the project reports about the topic. It was determined that articles of project reports were mostly indexed by Google Scholar. One important issue about the inclusion criterias was the selection of keywords. This study mainly focuses on the role of SPDAs and partly game related patterns in SPDA use which is frameworked with learning analytics view. Electronic performance support systems (EPSSs) are generally called performance-based systems and focus on the complete job. Also decision support systems (DSS) is focused on supporting and improving decision-making in action. The discrimination between the keywords used in this study and EPSS/DSS is also the difference between learning analytics view which reflects the data gathering step and implementation step (performance support/action view). In line with this, EPSS and DSS were not included to research corpus. 
The citation records of the Google Scholar were also benefited to expand the scope of review. A two-step inclusion criteria were used in the study as follows:

\section{First step}

At the first step the following criteria were used to choose the proper studies to be reviewed:

1. The studies which include predefined keywords in the titles

2. Those that deal with personal digital assistants which are based on smartness-intelligence

3. Those that evaluate the SPDAs in learning- and/or teaching-related contexts

4. Those studies that were published between 2010 and 2018

5. Those that are peer-reviewed research articles, conference papers, dissertations, book chapters and project reports

6. Those that can be accessible

The following criteria were used to exclude the studies from the scope of review:

1. The studies which are not written in English.

2. Those that were abstracts (one or two pages) or opinion papers or white papers

\section{Second step}

At the second step of the inclusion process the following criterion was taken into consideration: "The studies that include gamification or game related elements with the SPDAs".

Table 2. Number of studies included in the initial screening process

\begin{tabular}{lc}
\hline Search term & Number of studies screened \\
\hline "intelligent assistant" & 296 \\
"smart assistant" & 139 \\
"virtual assistant" & 229 \\
"artificial assistant" & 53 \\
"interactive assistant" & 141 \\
"personal digital assistant" & 94 \\
"personal assistant \& learning" & 6 \\
"personal assistant \& teaching" & 2 \\
"personal assistant \& education" & 6 \\
\hline
\end{tabular}

\section{Data Collection and Data Analysis}

In the screening process, a total of 966 studies were identified as shown in Table 2. A two round paper identification procedure was implemented after online searching process. In the first phase, after removing duplicates and a set of inclusion and exclusion criteria were implemented, 194 publications identified for the double review. In the second phase, the author and an educational technology expert evaluated the educational relatedness (subject area of publication) of the selected publications once again to provide refinement about actual educational publications. (For example medical or assistive techology solutions, papers about educational software design processes or educational application scenarios were excluded). Researchers continued their analysis with a total of 78 publications that succesfully met the inclusion criteria. In this round of the study, Cohen Kappa statistic was used to determine the coefficient of interrater reliability, in order to increase the dependability/confirmability of the research. The interrater reliability between the raters was calculated as $\mathrm{K}=0.914$ which indicates a perfect fit between the raters (Landis and Koch, 1977). Disagreed issues were also discussed in this process within the raters to reach a final concensus. In the study also a two-step review and analysis process was used to synthese the related literature. In the first phase, the abstracts of the studies were examined to identify those papers which evaluate the SPDAs in teaching and learning-related contexts. It was continued by examining learning contexts, results and conclusion sections of included papers. At the second step of the study the previously included papers but 
with no reference to gamification or game related elements in the teaching and learning process were excluded. The remaining papers $(n=16)$ were analysed in terms of the use of the gamification-related components in the teaching and learning process. Next the thematic analysis and content analysis were employed using the Microsoft Excel and NVivo 12 qualitative analysis software. The data collection and analysis process are summarized in Figure 1.

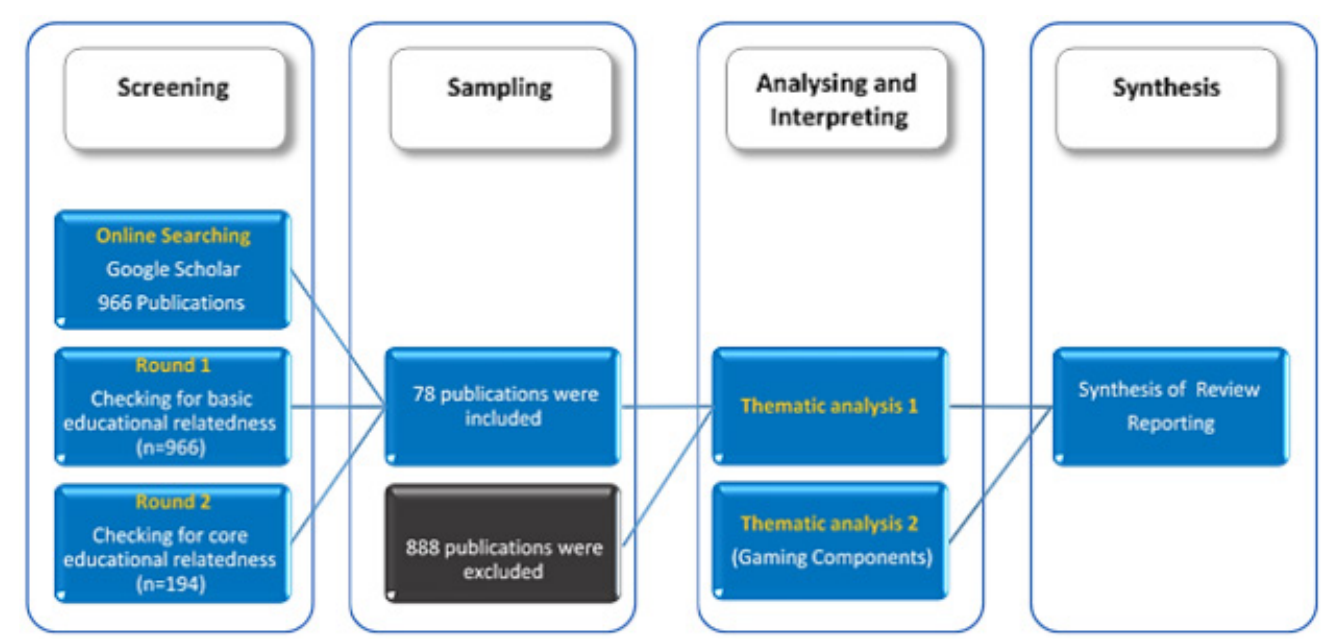

Figure 1. Data collection and data analysis process (adapted from Koseoglu \& Bozkurt, 2018)

In the thematic analysis process, the coefficient of interrater reliability was calculated once again. In this round, an intrarater reliability was also determined. The researcher repeated the thematic analysis 30 days after conducting the first analysis to reach an intrarater reliability. The interrater and intrarater reliability coefficients between the raters were respectively calculated as $\mathrm{K}=0.791$ and $\mathrm{K}=0.940$. Therefore, the reliability of Cohen Kappa values for this study can be considered as quite acceptable.

\section{Limitations and Significance of the Study}

The findings of the study are limited to the data taken from the researched articles published in peer-review academic journals, conference papers, dissertations and book chapters. These papers were all selected based on the inclusion criteria explained above. The date 2010 was specially determined because of the fact that influental mobile SPDA Siri was first launched in February 2010 as an iOS application. The mobile SPDAs have been developed and improved much since that year.

The studies reviewed in this study were found and listed via Google Scholar, Scopus, Web of Science, Proquest indexes, CORDIS research repository, and they were all written in English. This criterion limits the sample in that the papers which may also provide significant findings about the topic were to be excluded. Also research reports were screened only from Google Scholar and CORDIS project repository. Although the articles of project reports were mostly indexed by Google Scholar, this may currently limit the research scope. Admittedly, it is very difficult to reach the project reports funded by different institutions. Another limitation of this study is that the data based on Google Scholar's advanced search options were used. More specifically, the "all in title" search option was employed to narrow the research scope to be able to focus on the study subject. In other words, as a result of it some other significant studies may have been excluded from the scope of the present study.

The strengths of the study lie in the review of the studies concerning the gamification-related issues about the SPDAs which defined them as digital playmates of humans, namely roboludens. It is also considered to be significant to describe a novel interaction model/visualisation about learning analytics by this study. This is the main focus and significance of the present study. 


\section{FINDINGS AND DISCUSSION}

In this study a total of 78 studies about the SPDAs were reviewed and interpreted. The findings obtained are presented in two main sections, namely context mapping \& edu-centric findings and game-related findings.

\section{Context Mapping \& Edu-Centric Findings}

As shown in Figure 2, the SPDA-related educational studies relatively increased by 2014. Any specific estimation can be done in line with this data but it is possible to argue that this increased number of studies is a reflection of the tendency about using and integrating the SPDAs into educational contexts.

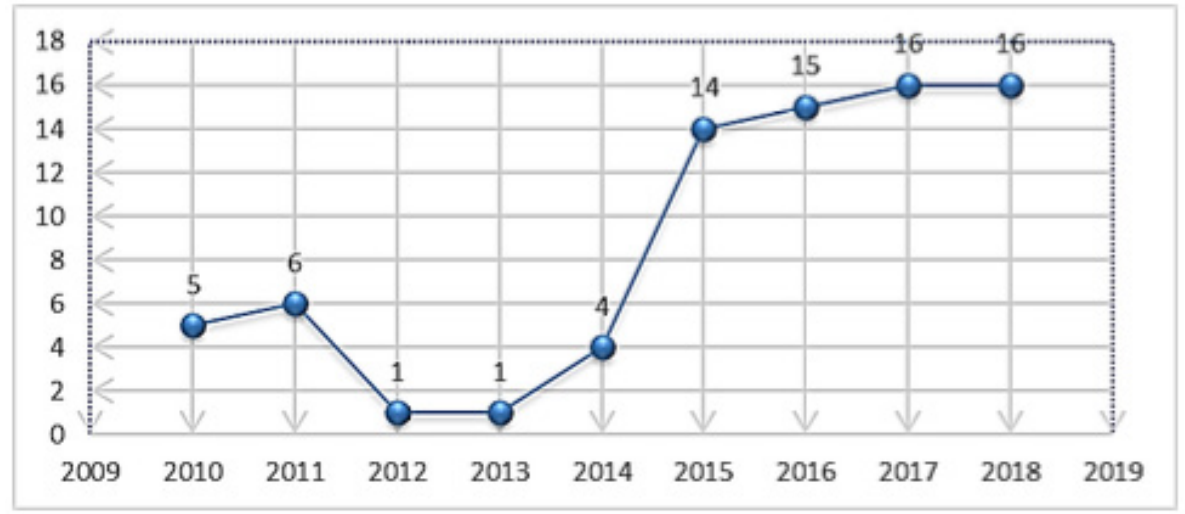

Figure 2. SPDA studies from 2010 to 2018

Another finding related to context mapping $\&$ edu-centric findings is nature and designs of the studies. As shown in Figure 3, system arcitecture papers which are explanatory in nature were the most dominant paper designs $(48,72 \%)$ among the papers reviewed. However, they may not be be considered as a methodological approach. In line with this consideration, it is possible to indicate that descriptive studies $(12,82 \%)$ and survey designs $(10,26 \%)$ were together the most frequently used quantitative approaches.

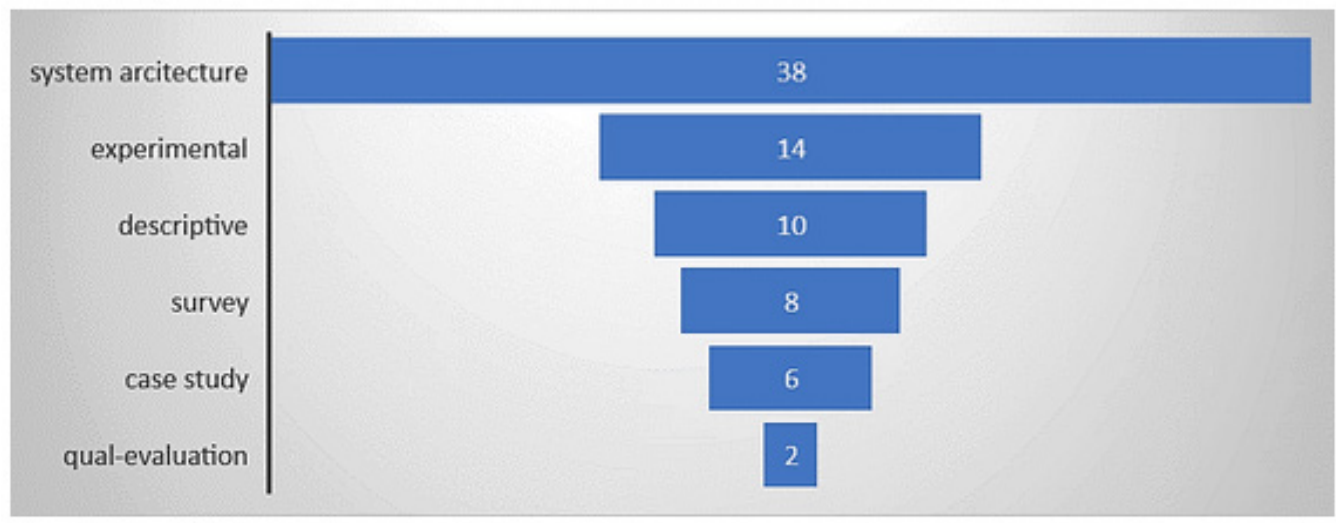

Figure 3. The nature and design of researches

Experimental research designs were also one of the most frequent research types among papers (17,95\%). The relatively small number of experimental designs is not an unexpected result, in line with the difficulties related to randomization in educational settings (Scott \& Usher, 2011). According to frequencies in this study, it can be argued that SPDA studies in educational settings are strongly related with the design and experimental control of the design. 
Another finding concerning the context mapping is about the genre of the studies reviewed in this study (Figure 4). Although peer reviewed articles, conference papers, academic dissertations, project reports and book chapters were the main data sources, the conference papers were the most frequent publication type $(70,5 \%)$.

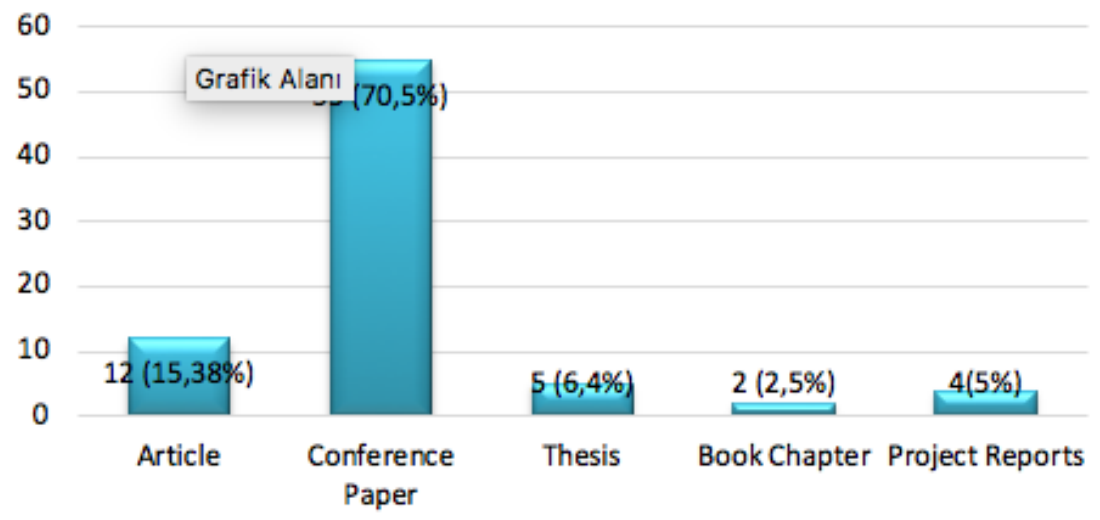

Figure 4. Genres of the studies reviewed

This finding is not surprising given that the SPDA use and integration into the teaching and learning environments are relatively new. The conference presentations are very common way to share, discuss and get immediate feedback about the studies on the new educational technologies. Therefore, it can be argued that the SPDA use and integration into the educational environments are still in primary testing stages and not fully postulated.

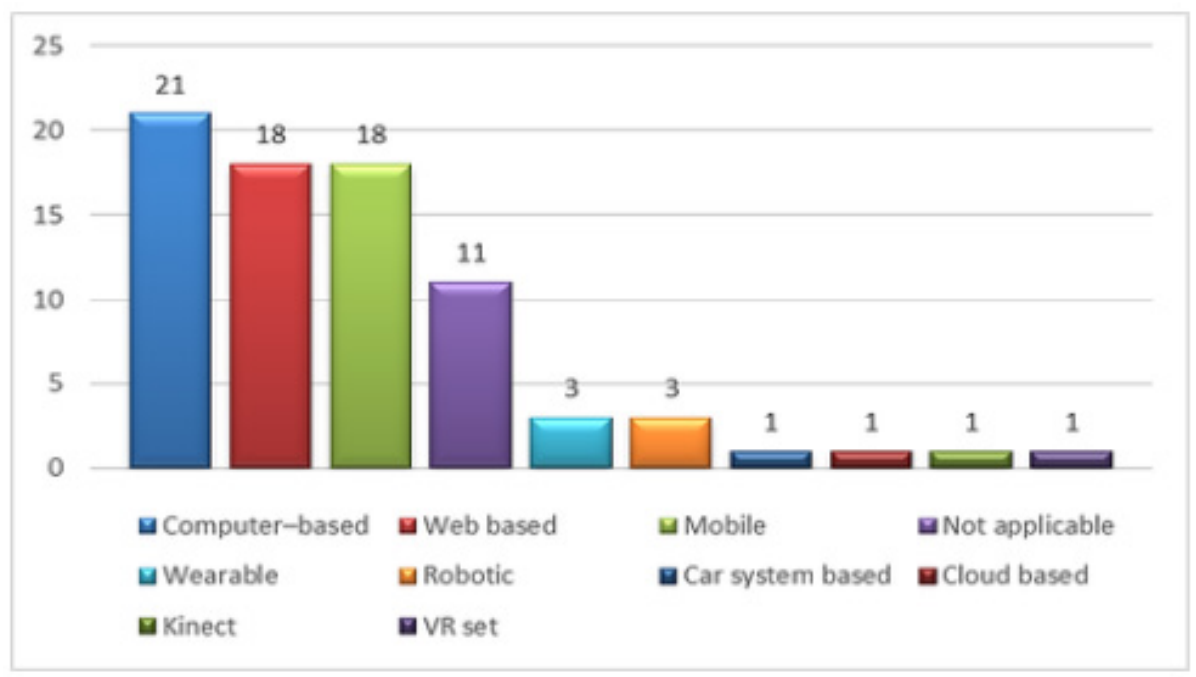

Figure 5. The mediator technologies which SPDAs are involved in

The mediator technologies in which the SPDAs are involved were reviewed in the current study, and the findings are shown in Figure 5. It is seen that computer based, web based, and mobile mediator technologies were dominant mediators for implementing the SPDAs. At this point it is significant to indicate that the computer based use of the SPDAs is not available to be used in mobiles. Also, the web architectured SPDAs seem not to be suitable for both computer based use or mobiles. Therefore, it can also be argued that the SPDA integration into any edu-centric environments is still in infancy period. 


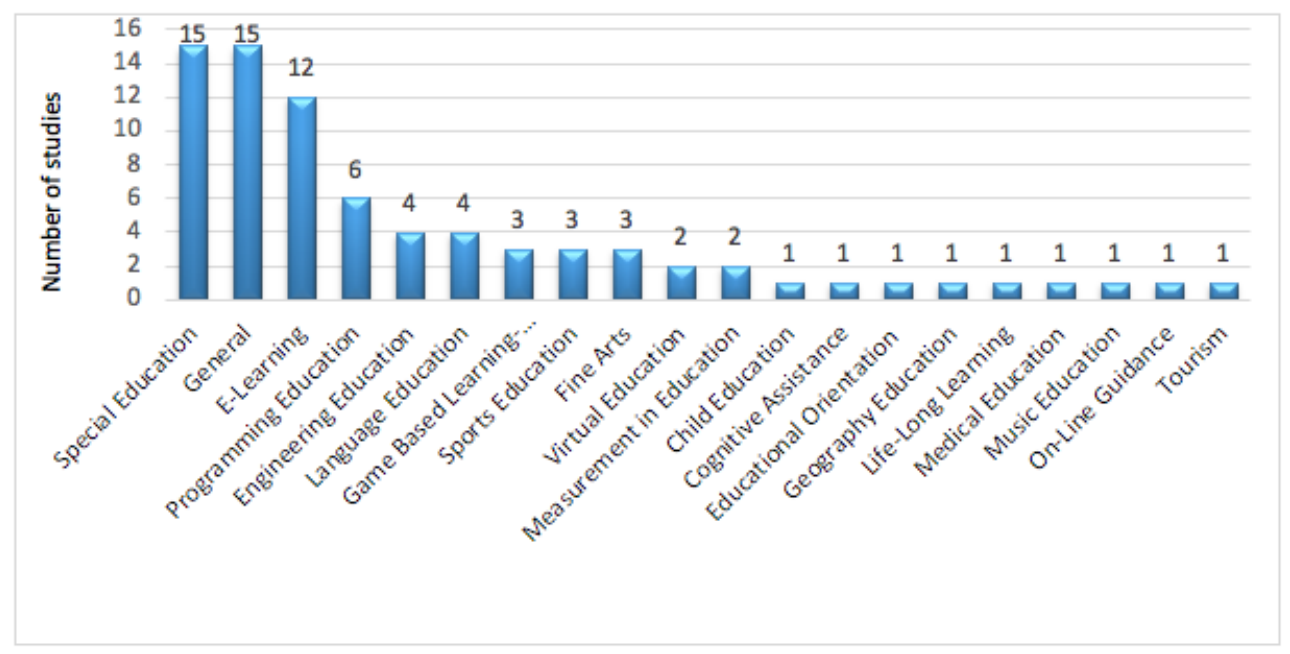

Figure 6. SPDA use in education/learning related domains

The use of the SPDAs in education/learning related domains in the studies reviewed are shown in Figure 6. As a birds-eye perspective, it is seen that the most frequent domains of the use od the SPDAs involve e-learning, special education, programming education and engineering education. The category of "general" reflects the use of the SPDA for general educational purposes, including achieving the stated goals across the dynamic changes in the environment, assisting students in their learning processes, self-management-supporting timely recovery from possible misunderstandings, supporting users in selecting educational material from learning objects repositories, assisting social networking by promoting user interactions and resource usage, supporting learning performance, helping students to manage their learning, allowing students to access/obtain on-the-fly course materials customized to their needs and preferences and to promote the interaction, helping to visualize datas, stimulating the innovation of teaching of teachers, promoting conversational skills, quick assistance to visitors and students in field trips, simulating real-world experiences and helping students in their campus life. It can be argued that the current significant fields for the use of the SPDAs are dominantly e-learning and special education. Parallel with the findings of a related research, SPDA use in any field of education is a promising emerging research area (Bozkurt \& Goksel, 2018) in line with technological breakthrough.

\section{Game-Related Findings}

The studies reviewed in this current study were also analysed in terms of their findings about the gamerelated components. Of 78 studies reviewed 16 included such components. The possible area of usage of the SPDAs concerning the game related components are identified as follows; socialising, exploring and accessing educational and cultural resources, simulating real-world experiences, helping students in virtual science experiments, asking questions to learners about specific lessons, mediating interaction with children in some cases (for example entertaining children in the back seat of a car. This is also engaging, entertaining and educating children), improving communication and interaction with authentic learning context, enhancing students' learning experience and has the potential to improve retention, progression and student achievement, learning about home modifications, guiding learners toward a broad array of resources that can help them learn, immediate learning support, providing quick assistance to visitors and students in museum or field trips, providing suitable courseware by identifying a child specifically based on the behavioural patterns that aids the autistic student's learning, providing feedback for personalized education which leads to an improved mentorship quality, helping students in their campus life and providing language rehabilitation. In addition, the game-based or gamification-based elements of the studies reviewed were analysed, and the findings are shown in Table 3. 
Table 3. Game-centric components of the studies reviewed

\begin{tabular}{llll}
\hline Game components & $\mathrm{n}$ & Game components & $\mathrm{n}$ \\
\hline virtual character & 7 & rewards & 1 \\
chatbot & 6 & visual aids & 1 \\
avatar & 3 & levels & 1 \\
virtual exploratory environment & 2 & leaderboards & 1 \\
points & 2 & unlocking & 1 \\
customization & 2 & roadmap & 1 \\
a real-world scenario & 1 & real-time monitoring & 1 \\
social engagement mechanism & 1 & immediate feedback & 1 \\
jumping to a particular area & 1 & &
\end{tabular}

One of the notable findings indicates that virtual characters, chatbots and avatars are the most used components of the use of game-centric SPDAs. This finding provides clues in line with gamified use of SPDAs as a playmates of individuals for educational purposes, that is, one of the research questions of this current study. Animated virtual agents and chatbots focus on one to one interaction with the user. They tend to act as playmates of users to assist them in different learning cases. As parallel with the Falloon's research (2010), virtual characters have a high motivational and learning engager value that reflects very positive educational outcomes. Therefore, they may be effective components in gathering learning analytics from learners to be used for educational purposes.

Feedback is the core process in educational processes as well as in any gamified environments (Sezgin, 2018). In the light of this, the author paid special attention to feeedback component given in the studies reviewed. It is concluded that although there is only one study which reported a component about feedback, most of the publications put emphasis on feedback component implicitly. As it is known, feedback is one of the core mechanisms where interaction takes place in all educational processes.

When the subject areas of the studies reviewed at the second part of the study, it is found that e-learning is the predominant field (50\%) for the game-centric SPDA studies. In addition, the conference papers (75\%) are the most frequent type of the studies reviewed which is parallel to the first step of analysis (general SPDA use in education). Also it can be argued that gamified SPDA use was boomed by 2015 (13 of 16 researches were made between 2015 and 2018). This proves the argument of gamification and SPDA integration in practical use at education-centric environments are new and still in primary testing stages.

One of the interesting findings based on the second part of the analysis reveals that there is an ambiguity between "avatars" and "virtual characters". Even they may have similiar representations and outlook, avatars are the animated representations of users and generally controlled by users in a game environment.

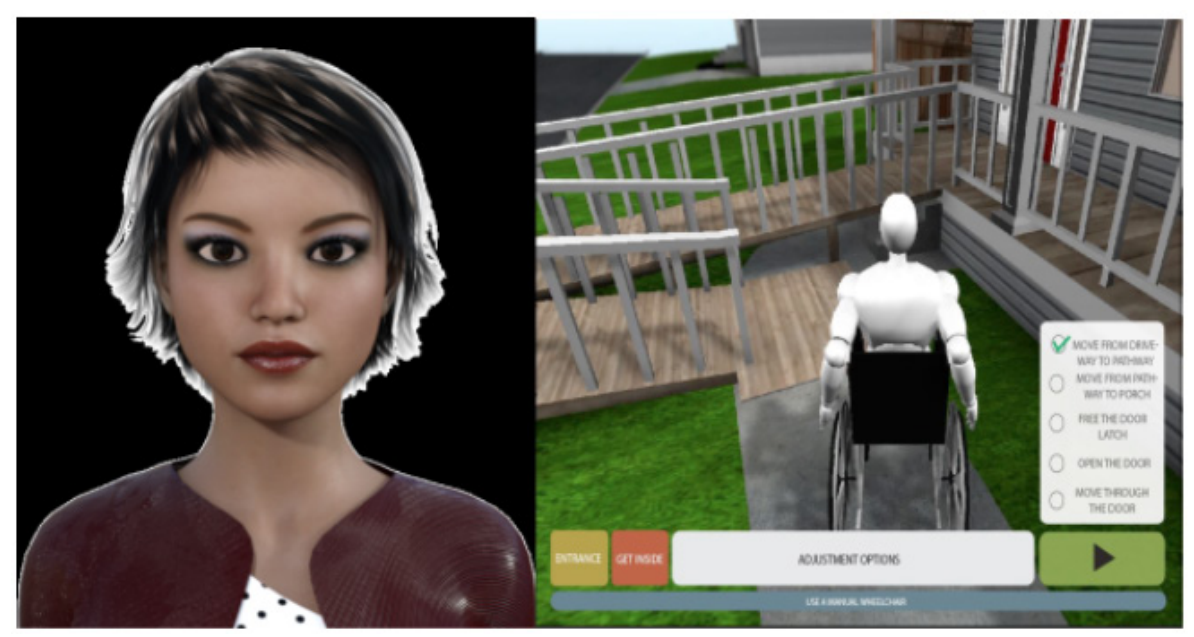

Figure 7. Virtual character (Rajagopal \& Babu, 2018) \& avatar (Milchus, Swarts, Malesevic \& Lee, 2015) 
Avatars provide simulation based real time presence to users. However, the animated virtual characters represent any character as part of the initally structured scenerio. As stated earlier the virtual agents and chatbots are very popular due to their animated /gameful presence. One of the most important game-based tools are supposed to be virtual representations of individuals in the gameful world of future. This finding is significant in line with this perspective however it is not the main focus of this review. It is a known fact that emotional engagement and connection are the two important factors supported by virtual agents (Taylor, 2011). Also learners can gather information through interacting with virtual characters (Wu, Lee, Chang, \& Liang, 2013). Other game related components like points, rewards, leaderboards, levels, unlocking new features and real-time monitoring, etc. may also play critical roles to gamifying the symbiotic learning process as well as gathering required learning analytics.

According to another finding, it was observed that there is a trend about designing new SPDAs apart from the most known SPDAs including Siri, Cortana and others. Jill Watson (Goel \& Polepeddi, 2016), Nicky (Kincaid \& Pollock, 2017), Maria (Rajagopal \& Babu, 2018) PseduoEye (Daraghmi \& Yosef, 2016), LABTA (Yang, 2010), BoBi (Liu \& Zhu, 2017), Project Nethra (Weeratunga, Jayawardana, Hasindu, Prashan, \& Thelijjagoda, 2015), LiSa (Dibitonto, Leszczynska, Tazzi, \& Medaglia, 2018), and Scarlet (Ilhan, Music, Junuz, \& Mirza, 2017) are some of the SPDAs specifically designed for educational purposes. There are also studies (Bravo, Paliyawan, Harada, \& Thawonmas, 2017; Huang, Chang, Chen, \& Chen, 2014; Lv \& Li, 2015) that use the body-motion preference systems such as eye-tracking, kinect and VR headsets. In two studies (Bogdan, Yurchenko, Bailo, Rameau, Yoo, \& Kweon, 2017; Bouloutian \& Kim, 2014) the SPDAs are integrated to wearable technologies. This finding indicate that the SPDAs are in development process as epiphytic systems and can be used as human body-integrated devices. Among these findings, there are only a few negative estimations and concerns about SPDA use in educational contexts. These are; ethical issues in using body integrated devices, personal data privacy in some of the data gathering methods of personal assistants, exhaustive big data components (gathering daily life analytics) and costs of production.

Results of meta-synthesis were clustured into three sections. Accordingly, SPDAs can be used in educational settings as follows:

\section{Possible SPDA use in special education}

- Help visually disabled to access social media and other internet based educational services by natural language processing

- Reduces the difficulty of reading a document for the blind or visually impaired person as a personal virtual friend

- Guiding to learn how to program for visually impaired

- Helping interaction with authistic children by virtual characters

- Provide suitable courseware by identifying a child specifically based on the behavioural patterns that aids the autistic student's learning

- Overcoming language defections with natural language processing and provide language rehabilitation

- Assisting hearing-impaired people for communication in learning processes

- Obtain an extensive feedback about their surrounding educational or authentic environment for physically or visually impaired individuals

\section{Possible SPDA use in E-learning}

- Guiding learners towards a broad array of resources that can help them learn.

- Answering the learners frequently asked questions at anytime and also provide immediate support

- To guide and assist students in solving their experimental problems.

- To improve communication and interaction with any learning platform.

- Automatically grade student work, provide immediate feedback, and to guide students through the problem-solving process

- Providing individualised "valuable feedback" which leads to an improved mentorship quality

- Enhancing students' learning experience and has the potential to improve retention, progression and student achievement by attention-grabbing interactional features 
- Helping learners in virtual science experiments.

- Providing distance training for high probable risk areas like power plant operation

\section{Possible SPDA use in other educational settings}

- Removing language barriers with the help of synchronous translation programs, helping learners' pronunciation skills, providing timely recovery from possible misunderstandings.

- Supporting learners with authentic virtual field trips with quick assistance

- Adapting individuals to daily or complex conversations who has social disorders

- Providing support for individuals who have disorders or inabilities about their mental persistence to any learning process

- Supporting learners at hands-on, hands free and learning by doing situations (with wearables or oral commands)

- Complex and stressful problems can be solved as a quick knowledge navigation tools

- Provides 24/7 accessibility, self-paced learning and personalized instructions for shy or more timid students.

- Allowing to implement one-to-one guiding and individualized practical training in programming courses (identifying error codes, helping students practice program tracing, support learners in their programming assignments)

- Automatically suggesting educational or course materials customized to learner analytics hence allowing learners to control their university education

- Providing immediate feedback thus self-evaluation in fine arts or sports education where individual guidance is very significant (Dance-teaching, singing breath control process, doing sketching and shading, learn the art of archery, professional volleyball training).

- Helping learners in their campus life by diversified guidance features

- Providing technical assistant when using electronic components for technical education domains.

- Helping to interact with children in car travels with an engaging and entertaining way for educational purposes.

- Helping learners to relieve some of the pressure in their daily tasks and studies by a conversational friend.

Also according to literature synthesis, SPDAs can be used under the guidance of gamification techniques with mobiles or wearables in educational settings as follows;

- Accessing and processing real daily life logs and learning analytics of learners instantaneously and provide more individualised-specialized learning environments

- Gamifying learning and support learners with motivation and engagement by the power of game elements.

- Supporting learners with quick responses and recommendations in different situational learning scenarios which must be gamified due to strain or difficulty of the learning case

- Engage to authentic learning situations using natural language dialogues

In line with the reviewed publications in this current study, it was seen that there is a strong emphasis on the structural form of SPDAs. The common features of SPDAs were determined as; natural language processing, animated virtual appearance with conversational infrastructure, epiphytic habit, responding to dynamic changes in the learning environment with artificial intelligence, aiding decision making and data gathering abilities.

Based on the synthesis of the findings, a basic level conceptual visualisation was generated as shown in Figure 8. In the new data-oriented world, data gathering process from individuals is a vital requirement for individualised learning. By the help of mobiles and wearables, SPDAs were become widespread. This provided a close relationship between humans and humanoid friends but at this point the critical question revealed: "how can be accessed and gathered real daily life logs and learning analytics of learners instantaneously especially in authentic learning scenarios?". In the new data driven era SPDAs are becoming data gathering 
tools via gamified behaviours. Therefore, the figurative term for SPDAs, roboludens, may be an inovative game-changer for the future of learning.

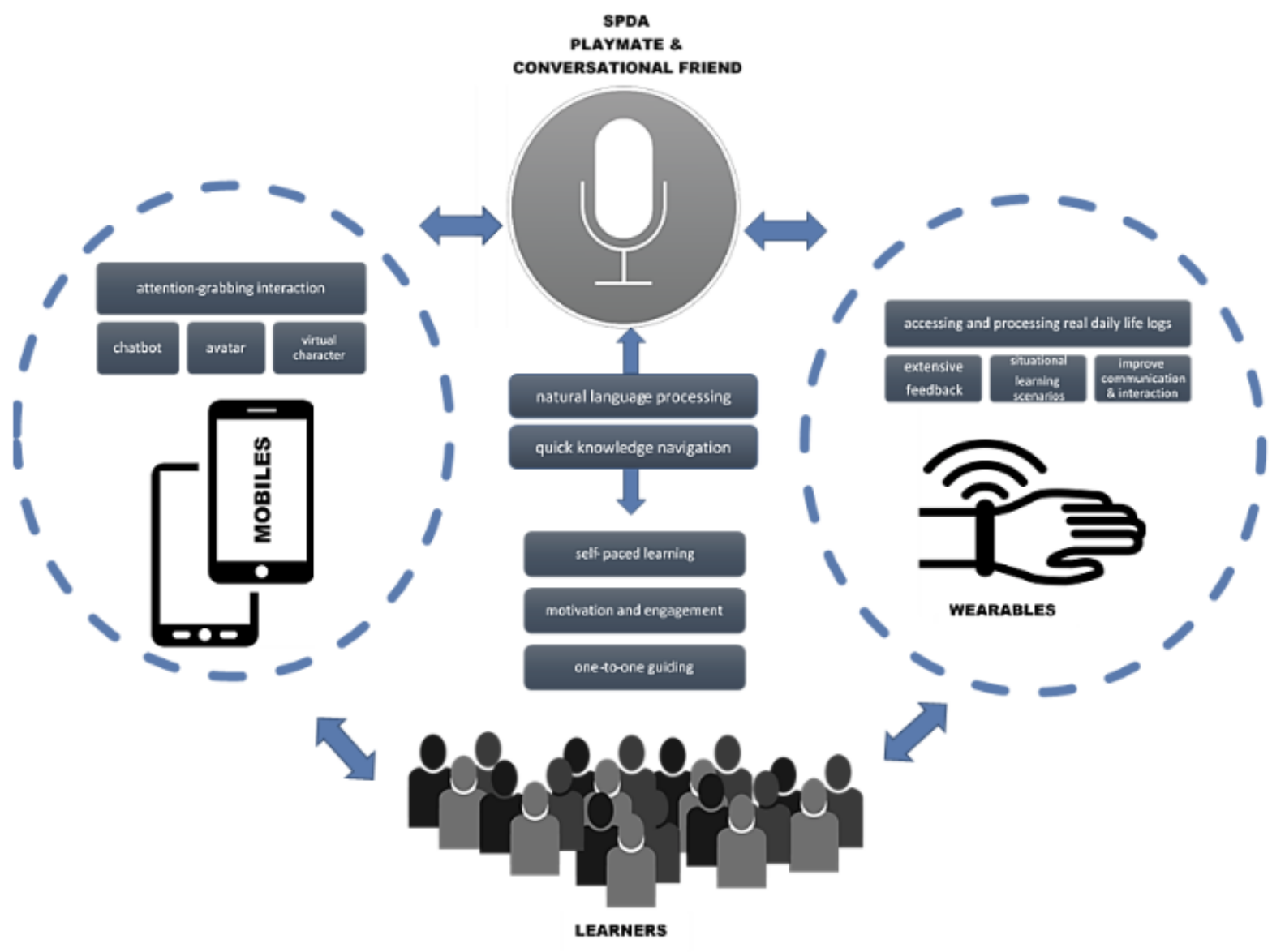

Figure 8. Conceptual visualisation of SPDAs as "data gathering tools"

\section{CONCLUSION AND FUTURE IMPLICATIONS}

This current study shows the dispersion of SPDA use in education/learning related subject domains. More than 19 different educational areas for the use of the SPDAs are identified in the study. It provides some insights about the capabilities and abilities of the SPDAs for educational purposes. Among these educational domains e-learning and special education are found to be the outnumbered areas for the use of the SPDAs. Therefore, it can be concluded that the current SPDAs are quite eligible to present rich learning experiences for distance learners and individuals with special needs.

One of the initial aims of this research was tracing the gamified elements among SPDA use in educational/ learning settings as playmates of humans. 16 studies were found to be eligible to included. Although virtual characters, chatbots, avatars and other game related components are being integrated with SPDAs, there was no empirical evidence about accessing real daily life logs of users by gamified actions and transfering them into educational settings as a duty of a smart assistant. However, research concludes that the SPDAs are in a transformational period for the use in learning proceses.

Insights and clues gained from this study indicate that SPDAs may have a critical role with embedded gamified actions. Thus, SPDAs are very likely to gain attention for educational settings because they shed light on the very basic instricts of humankind, gamefulness. Based on the findings of the study, the following suggestions can be considered for the future of SPDA use in educentric purposes. First, fully understanding the needs of any learner group is essential for educators or learning designers to integrate SPDAs for adaptive learning plans/scenarios. Because these plans/scenarios are based on the learning/daily life analytics of 
learners. Second, new strategies and policies need to be developed to eliminate barriers in ethical and data privacy issues about the data gathering procedures of SPDAs. Third, educational technology labs in different faculties and schools will help to understand the dynamics and features of such artificially intelligent high technology devices. Finally the relationship between the big data, learning analytics, gamification and wearables/mobiles must be explored attentively to provide new technology integration models for different domains of education.

There is a strong relationship between the SPDAs and the gamification in the IoT era. Digital assistants are the artificial structures and possibly living on mobile devices and also wearables. They enrich and ease the life and experiences of individuals through their humanoid artificial intelligence. This is very likely to become a standart in the near future. Education systems of the near future must aim at providing richer and more efficient learning experiences by integrating the whole life experiences into education process. Therefore, gameful virtual friends; roboludens may have a critical role for accessing and processing real daily life logs and learning analytics of learners instantaneously and provide more individualised-specialized learning environments.

\section{BIODATA and CONTACT ADDRESSES of AUTHOR}

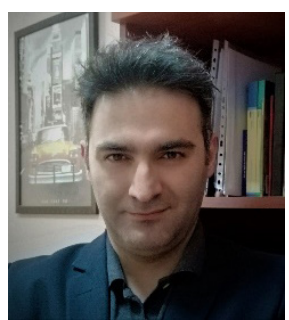

Dr. Sezan SEZGIN is a researcher at Faculty of Education, Burdur Mehmet Akif Ersoy University. Dr. Sezgin holds M.S and Ph.D. degrees in Distance Education. He teaches graduate courses on instructional design and research methods. His academic interest areas are online course design, learning analytics, digital gamification, social network analysis, teacher professional development, lifelong learning, and wearable technologies. His work has been presented and published in several national and international venues.

Sezan SEZGIN

Computer Education and Instructional Technologies Department, Faculty of Education

Address: Burdur Mehmet Akif Ersoy University, 15100, Burdur, Turkey

Phone: +902482134067

E-mail: sezansezgin@mehmetakif.edu.tr

\section{REFERENCES}

Back, W. D., Zant, T., \& Zwanepol Klinkmeijer, L. (2001). Robo Sapiens. Proceedings of the First Dutch Symposium on Embodied Intelligence. Artificial Intelligence Preprint Series, 24.

Baker, R. S., \& Inventado, P. S. (2014). Educational data mining and learning analytics. In Learning analytics (pp. 61-75). Springer, New York, NY.

Bogdan, O., Yurchenko, O., Bailo, O., Rameau, F., Yoo, D., \& Kweon, I. S. (2017, November). Intelligent Assistant for People with Low Vision Abilities. In Pacific-Rim Symposium on Image and Video Technology (pp. 448-462). Springer, Cham.

Bouloutian, S., \& Kim, E. (2014, December). Artificial Intelligence Gaming Assistant for Google Glass. In International Symposium on Visual Computing (pp. 770-778). Springer, Cham.

Bozkurt, A., Goksel, N. (2018). Technology renovates itself: Key concepts on intelligent personal assistants (IPAs). In EDULEARN18 Proceedings, pp. 4291-4297.

Bravo, J. A. M., Paliyawan, P., Harada, T., \& Thawonmas, R. (2017, October). Intelligent assistant for providing instructions and recommending motions during full-body motion gaming. In Consumer Electronics (GCCE), 2017 IEEE 6th Global Conference on (pp. 1-2). IEEE.

Coursen, J. (2011). Against Species Extinction Transhumanism and Contemporary Technological Culture. Tirosh-Samuelson, H., \& Mossman, K. L. (Eds.). In Building better humans?: Refocusing the debate on transhumanism (p. 417-441). Frankfurt: Peter Lang. 
Daraghmi, E. Y., \& Yosef, R. (2016). PseduoEye: An Interactive Augmented Reality Assistant App for Electronic Engineering Students. International Journal of Computer Science and Mobile Applications, $4(10)$.

Dibitonto, M., Leszczynska, K., Tazzi, F., \& Medaglia, C. M. (2018, July). Chatbot in a Campus Environment: Design of LiSA, a Virtual Assistant to Help Students in Their University Life. In International Conference on Human-Computer Interaction (pp. 103-116). Springer, Cham.

Falloon, G. (2010). Using avatars and virtual environments in learning: What do they have to offer?. British Journal of Educational Technology, 41(1), 108-122.

Goel, A. K., \& Polepeddi, L. (2016). Jill Watson: A Virtual Teaching Assistant for Online Education. Georgia Institute of Technology.

Gomez, C., Chessa, S., Fleury, A., Roussos, G., \& Preuveneers, D. (2019). Internet of Things for enabling smart environments: A technology-centric perspective. Journal of Ambient Intelligence and Smart Environments, 11(1), 23-43.

Grant, A. S. (2019). Will Human Potential Carry Us Beyond Human? A Humanistic Inquiry Into Transhumanism. Journal of Humanistic Psychology, 0022167819832385.

Guadagno, R. E., Okdie, B. M., \& Muscanell, N. L. (2013). Have we all Just Become "Robo-Sapiens"? Reflections on social influence processes in the Internet age. psychological inquiry, 24(4), 301-309.

Gutierrez-Jones, C. (2014). Stealing Kinship: Neuromancer and Artificial Intelligence. Science Fiction Studies, 41(1), 69-92.

Hall, C., Tillman, M. (2018). What is Bixby? Samsung's smart assistant explained Retrieved from https:// www.pocket-lint.com/phones/news/samsung/140128-what-is-bixby-samsungs-assistantexplained-and-how-to-use-it Last accessed 10 December 2018

Hayles, N. K. (1999). How we became posthuman: Virtual bodies in cybernetics, literature, and informatics. University of Chicago Press.

Huang, C. J., Chang, S. C., Chen, H. M., \& Chen, C. Y. (2014, October). Performance evaluation of an intelligent multimedia learning assistant platform. In Frontiers in Education Conference (FIE), 2014 IEEE (pp. 1-7). IEEE.

Huizinga, J. (1955). Homo Ludens: A Study of the Play Element in Culture. Boston: The Beacon Press.

Iantorno, M. (2015). Conceptualizing Robots as Playmates and Playthings (Doctoral dissertation, York University Toronto).

Ilhan, K., Music, D., Junuz, E., \& Mirza, S. (2017, May). Scarlet-Artificial Teaching Assistant. In Control, Artificial Intelligence, Robotics \& Optimization (ICCAIRO), 2017 International Conference on (pp. 11-14). IEEE.

Kanda, T., Hirano, T., Eaton, D., \& Ishiguro, H. (2004). Interactive robots as social partners and peer tutors for children: A field trial. Human-Computer Interaction, 19(1-2), 61-84.

Kim, M. S., Gong. L, Saito. N, Nishigaya. K, Cabico. M, \& LaFontaine. P. (2011). The role of self-construal on preferred communication styles with humanoid robots. Int J HR 8:359-374

Kim, M. S., \& Kim, E. J. (2013). Humanoid robots as "The Cultural Other": are we able to love our creations?. AI \& society, 28(3), 309-318.

Kincaid, R., \& Pollock, G. (2017, January). Nicky: Toward a Virtual Assistant for Test and Measurement Instrument Recommendations. In Semantic Computing (ICSC), 2017 IEEE 11th International Conference on (pp. 196-203). IEEE.

Klinger, M. B., \& Coffman, T. L. (2019). Transforming the Classroom Experience Through Transhumanism: Education as the Learning Organization. In Handbook of Research on Learning in the Age of Transhumanism (pp. 134-156). IGI Global.

Knoll, A. (2002). Cui bono robo sapiens?. Autonomous Robots, 12(1), 5-12 
Koseoglu, S., \& Bozkurt, A. (2018). An exploratory literature review on open educational practices. Distance Education, 39(4), 441-461.

Liu, J., \& Zhu, B. (2017). An intelligent personal assistant robot: BoBi secretary. In 2017 2nd International Conference on Advanced Robotics and Mechatronics (ICARM)(pp. 402-407). IEEE

Lv, Z., \& Li, X. (2015, November). Virtual reality assistant technology for learning primary geography. In International Conference on Web-Based Learning (pp. 31-40). Springer, Cham

Maedche, A., Legner, C., Benlian, A., Berger, B., Gimpel, H., Hess, T., ... \& Sollner, M. (2019). AI-Based Digital Assistants. Business \& Information Systems Engineering, 1-10.

Mercer, C., \& Trothen, T. J. (Eds.). (2014). Religion and Transhumanism: The Unknown Future of Human Enhancement: The Unknown Future of Human Enhancement. ABC-CLIO.

Milchus, K., Swarts, M., Malesevic, M., \& Lee, S. J. (2015). The Virtual Home Modifications Educational Assistant In Proceedings of RESNA Annual Conference.

Moravec, H. (1999). Robot: Mere Machine to Transcendent Mind. New York: Oxford University Press

More, M. (1999). Extropian Principles 3.0: A Transhumanist Declaration. ExI: Extropy Institute. Retrieved from http://www.extropy.org/ideas/principles.html Last accessed 02 December 2018

Negrete-Martinez, J. (2005). Three Steps to Robo Sapiens. In International Workshop on Rough Sets, Fuzzy Sets, Data Mining, and Granular-Soft Computing (pp. 727-733). Springer, Berlin, Heidelberg.

Nieva, R. (2018). "Google Assistant's one step closer to passing the Turing test". CNET. Retrieved May 10, 2018. https://www.cnet.com/news/google-assistant-duplex-at-io-could-become-the-most-lifelikeai-voice-assistant-yet/

O'Boyle, B., Grabham, D. (2018). What is Alexa and what can Amazon Echo do? Retrieved from https:// www.pocket-lint.com/smart-home/news/amazon/138846-what-is-alexa-how-does-it-work-andwhat-can-amazons-alexa-do Last accessed 10 December 2018

Petticrew, M., \& Roberts, H. (2005). Systematic reviews in the social sciences. A practical guide. London: Blackwell.

Postman, N. (1993). Technopoly: The Surrender of Culture to Technology. New York: Vintage Books.

Rajagopal, M., \& Babu, M. (2018). Virtual Teaching Assistant to Support Students' Efforts in Programming (Doctoral dissertation, Virginia Tech).

Rushe, D. (2010) Dawn of the age of the robot: advancement in robotics will dominate next decade, says head of the Institute for the Future. The Guardian, 29 Dec 2010. http://www.guardian.co.uk/ business/2010/dec/30/futurologist-predicts-age-of-robots. Retrieved 12 September 2018

Scott, D., \& Usher, R. (2011). Researching education. London, UK: Continuum

Sezgin, S. (2018). Analysing adaptive gamification design principles for online courses. Doctoral dissertation, Anadolu University.

Sezgin, S., Bozkurt, A., Yilmaz, E. A., \& van der Linden, N.(2018). Oyunlastirma, Egitim ve Kuramsal Yaklasimlar: Ogrenme Sureclerinde Motivasyon, Adanmislik ve Surdurebilirlik. Mehmet Akif Ersoy Universitesi Egitim Fakultesi Dergisi, (45), 169-189.

Sezgin, S., \& Yuzer, T. V. (2017). Games As Futuristic Tools: Looking For An Advanced Definition. In Conference Proceedings of the 10th International Conference of Education, Research and Innovation ICERI (pp. 8512-8521).

Siri (2018). In Wikipedia: The Free Encyclopedia 10 Agustos 2008 tarihinde https://en.wikipedia.org/wiki/ Siri Last accessed 02 June 2018

Soma, N. (2018). Utopia of 81 Squares: Harmony between homo/robo ludens in Shogi and Chess. In Proceedings of the 32nd Annual Conference of the Japanese Society for Artificial Intelligence. The Japanese Society for Artificial Intelligence 
Taylor, L. D. (2011). Avatars and emotional engagement in asynchronous online communication. Cyberpsychology, Behavior, and Social Networking, 14(4), 207-212.

Tirosh-Samuelson, H., \& Mossman, K. L. (2011). New perspectives on transhumanism. Building better humans?: Refocusing the debate on transhumanism (p.29-52). Frankfurt: Peter Lang.

Walsh, D., \& Downe, S. (2005). Meta-synthesis method for qualitative research: a literature review. Journal of advanced nursing, 50(2), 204-211.

Webster, J., \& Watson, R. T. (2002). Analyzing the past to prepare for the future: Writing a literature review. MIS Quarterly, 26(2), 13-23.

Weeratunga, A. M., Jayawardana, S. A. U., Hasindu, P. M. A. K., Prashan, W. P. M., \& Thelijjagoda, S. (2015). Project Nethra-an intelligent assistant for the visually disabled to interact with internet services. In Industrial and Information Systems (ICIIS), 2015 IEEE 10th International Conference on (pp. 55-59). IEEE.

Welch, C. (2017). Google Assistant will soon search by sight with your smartphone camera. The Verge. Vox Media. Retrieved from https://www.theverge.com/2017/5/17/15648128/google-assistantcamera-sight-search-feature-io-2017 Last accessed 10 December 2018

Wu, H. K., Lee, S. W. Y., Chang, H. Y., \& Liang, J. C. (2013). Current status, opportunities and challenges of augmented reality in education. Computers \& education, 62, 41-49.

Yang, C. (2010, December). LABTA: An Agent-Based Intelligent Teaching Assistant for Experiment Courses. In International Conference on Web-Based Learning (pp. 309-317). Springer, Berlin, Heidelberg. 